\title{
Activation of TRPA1 Channel Facilitates Excitatory Synaptic Transmission in Substantia Gelatinosa Neurons of the Adult Rat Spinal Cord
}

\author{
Masafumi Kosugi, ${ }^{1,2}$ Terumasa Nakatsuka, ${ }^{1}$ Tsugumi Fujita, ${ }^{1}$ Yasuo Kuroda, ${ }^{2}$ and Eiichi Kumamoto ${ }^{1}$ \\ Departments of ${ }^{1}$ Physiology and ${ }^{2}$ Neurology, Faculty of Medicine, Saga University, Saga 849-8501, Japan
}

TRPA1 is expressed in primary sensory neurons and hair cells, and it is proposed to be activated by cold stimuli, mechanical stimuli, or pungent ingredients. However, its role in regulating synaptic transmission has never been documented yet. In the present study, we examined whether activation of the TRPA1 channels affects synaptic transmission in substantia gelatinosa (SG) neurons of adult rat spinal cord slices by using the whole-cell patch-clamp technique. A chief ingredient of mustard oil, allyl isothiocyanate (AITC), superfused for 2 min markedly increased the frequency and amplitude of spontaneous EPSCs (sEPSCs), which was accompanied by an inward current. Similar actions were produced by cinnamaldehyde and allicin. The AITC-induced increases in SEPSC frequency and amplitude were resistant to tetrodotoxin (TTX) and $\mathrm{La}^{3+}$, whereas being significantly reduced in extent in $\mathrm{Ca}^{2+}$-free bath solution. In the presence of glutamate receptor antagonists CNQX and AP5, AITC did not generate any synaptic activities. The AITC-induced increases in sEPSC frequency and amplitude were reduced by ruthenium red, whereas being unaffected by capsazepine. AITC also increased the frequency and amplitude of spontaneous inhibitory postsynaptic currents; this AITC action was abolished in the presence of TTX or glutamate receptor antagonists. These results indicate that TRPA1 appears to be localized not only at presynaptic terminals on SG neurons to enhance glutamate release, but also in terminals of primary afferents innervating onto spinal inhibitory interneurons, which make synapses with SG neurons. This central modulation of sensory signals may be associated with physiological and pathological pain sensations.

Key words: channel; presynaptic facilitation; glutamate; patch clamp; pain; spinal cord

\section{Introduction}

Transient receptor potential (TRP) channels are homotetrameric or heterotetrameric polypeptides initially identified as photoreceptors and later recognized as nonselective cation channels in a variety of sensing apparatuses (Montell et al., 2002; Clapham, 2003; Nilius and Voets, 2005; Minke, 2006). TRP channels gate in response to a variety of chemical and physical stimuli including pungent agents, temperature, pain, lipids, acid, and shear stress (Tominaga and Caterina, 2004; Lin and Corey, 2005; Pedersen et al., 2005; Wang and Woolf, 2005). Thus far, the TRP superfamily can be subdivided into seven families: TRPC, TRPV, TRPM, TRPP, TRPML, TRPA, and TRPN family (Clapham, 2003; Nilius and Voets, 2005; Minke, 2006). TRPA is the newest family of TRP channels. TRPA 1 is found in a subset of primary sensory neurons in which it is coexpressed with noxious heat-sensing TRPV1 but not non-noxious cool-sensing TRPM8 (Story et al., 2003; Kobayashi et al., 2005). TRPA1 is activated by noxious cold temperature (Story et al., 2003) and pungent natural compounds in mus-

\footnotetext{
Received 0ct. 12, 2006; revised March 12, 2007; accepted March 18, 2007.

This work was supported by The General Insurance Association of Japan, The Japanese Health Sciences Foundation, and grants-in-aid for Scientific Research from the Ministry of Education, Science, Sports and Culture of Japan to T.N.

Correspondence should be addressed to Terumasa Nakatsuka, Department of Physiology, Faculty of Medicine, Saga University, Saga 849-8501, Japan. E-mail: nakatsuk@cc.saga-u.ac.jp.

D0I:10.1523/JNEUROSC1.0557-07.2007

Copyright $\odot 2007$ Society for Neuroscience $\quad$ 0270-6474/07/274443-09\$15.00/0
}

tard oil, cinnamon oil, ginger, and garlic (Bandell et al., 2004; Jordt et al., 2004; Bautista et al., 2006). Recent findings have indicated that TRPA1 is involved in not only cold transduction, but also mechanosensation, inflammatory hyperalgesia, and neuropathic pain (Namer et al., 2005; Obata et al., 2005). Moreover, it has been recently demonstrated that TRPA1 is also expressed in hair cells and it is proposed to mediate auditory transduction (Corey et al., 2004; Nagata et al., 2005). Although these peripheral roles of TRPA1 channel have been elucidated in the last few years, its role in the CNS has never been examined up to now.

Superficial laminas of the spinal dorsal horn, particularly the substantia gelatinosa (SG), receive nociceptive information from the viscera, skin, and other organs through primary afferent fibers (Willis and Coggeshall, 2004). Recently, molecular mechanisms of pain have been greatly advanced after the identification of TRPV1, P2X, and other molecules in nociceptive sensory neurons (Tominaga and Caterina, 2004; Nakatsuka and Gu, 2006). Interestingly, these pain-sensing channels are not only expressed at peripheral nerve endings but also found at central terminals of nociceptive primary afferent fibers innervating onto SG neurons (Nakatsuka et al., 2002). The presynaptic activation of TRPV1 and $\mathrm{P} 2 \mathrm{X}$ at central terminals modulates synaptic transmission by enhancing glutamate release, which contributes to the strength of the synaptic connection between primary afferent fibers and spinal dorsal horn neurons (Yang et al., 1998; Nakatsuka and Gu, 2001). Moreover, this central modulation by the activation of 
P2X and TRPV1 is associated with pathological pain sensations (Tsuda et al., 1999; Kelly and Chapman, 2002). However, it has never been addressed whether TRPA1 locates at central terminals of primary afferent fibers and whether its activation modulates synaptic transmission in the spinal dorsal horn. Therefore, the aim of this study was to evaluate whether TRPA1 is involved in modulating excitatory and inhibitory synaptic transmission in SG neurons of spinal cord slices.

\section{Materials and Methods}

All of the experimental procedures involving the use of animals were approved by the Ethics Committee on Animal Experiments, Saga University, and were in accordance with the United Kingdom Animals (Scientific Procedures) Act of 1986 and associated guidelines.

Spinal cord slice preparation. The methods used for obtaining adult rat spinal cord slice preparations have been described previously (Nakatsuka et al., 2000). In brief, male adult Sprague Dawley rats (6-8 weeks of age, $200-300 \mathrm{~g})$ were deeply anesthetized with urethane $(1.2 \mathrm{~g} / \mathrm{kg}$, i.p.) and then lumbosacral laminectomy was performed. The lumbosacral spinal cord (L1-S3) was removed and placed in preoxygenated Krebs' solution at $1-3^{\circ} \mathrm{C}$. Immediately after the removal of the spinal cord, the rats were given an overdose of urethane and were then killed by exsanguination. The pia-arachnoid membrane was removed after cutting all of the ventral and dorsal roots near the root entry zone. The spinal cord was mounted on a microslicer and then a $600-\mu \mathrm{m}$-thick transverse slice was cut. The slice was placed on nylon mesh in the recording chamber, which had a volume of $0.5 \mathrm{ml}$, and then perfused at a rate of $10-15 \mathrm{ml} / \mathrm{min}$ with Krebs' solution saturated with $95 \% \mathrm{O}_{2}$ and $5 \% \mathrm{CO}_{2}$, and maintained at $36 \pm 1{ }^{\circ} \mathrm{C}$. The Krebs' solution contained the following (in $\mathrm{mM}$ ): $117 \mathrm{NaCl}, 3.6 \mathrm{KCl}, 2.5 \mathrm{CaCl}_{2}, 1.2$ $\mathrm{MgCl}_{2}, 1.2 \mathrm{NaH}_{2} \mathrm{PO}_{4}, 25 \mathrm{NaHCO}_{3}$, and 11 glucose, $\mathrm{pH}$ 7.4.

Patch-clamp recordings from $S G$ neurons. Blind whole-cell patch-clamp recordings were made from SG neurons with patch-pipette electrodes having a resistance of 5-10 $\mathrm{M} \Omega$ (Nakatsuka et al., 2000). The patchpipette solution used to record EPSCs was composed of the following (in mM): 135 potassium gluconate, $5 \mathrm{KCl}, 0.5 \mathrm{CaCl}_{2}, 2 \mathrm{MgCl}_{2}, 5$ EGTA, 5 HEPES, and 5 ATP-Mg, pH 7.2. The patch-pipette solution used to record IPSCs was composed of the following (in mM): $110 \mathrm{Cs}_{2} \mathrm{SO}_{4}, 5$ tetraethylammonium (TEA), $0.5 \mathrm{CaCl}_{2}, 2 \mathrm{MgCl}_{2}, 5$ EGTA, 5 HEPES, and 5 ATP-Mg, pH 7.2. Signals were acquired with a patch-clamp amplifier (Axopatch 200B; Molecular Devices, Foster City, CA). Data were digitized with an analog-to-digital converter (Digidata 1322; Molecular Devices), stored, and analyzed with a personal computer using the pCLAMP data acquisition program (version 8.2; Molecular Devices). SG neurons were viable for up to $24 \mathrm{~h}$ in slices perfused with preoxygenated Krebs' solution. However, all of the recordings described here were obtained within $12 \mathrm{~h}$. Whole-cell patch-clamp recordings were stable for up to $4 \mathrm{~h}$.

Application of drugs. Drugs were dissolved in Krebs' solution and applied by perfusion via a three-way stopcock without any change in the perfusion rate or the temperature. The time necessary for the solution to flow from the stopcock to the surface of the spinal cord slice was $\sim 30 \mathrm{~s}$. The drugs used in this study were allyl isothiocyanate (AITC), capsaicin, capsazepine, tetrodotoxin (TTX), ruthenium red (Wako, Osaka, Japan), cinnamaldehyde (CA), allicin, 6-cyano-7-nitroquinoxaline-2,3-dione (CNQX), and DL-2-amino-5-phosphonopentanoic acid (AP5; Sigma, St. Louis, MO). AITC, CA, allicin, capsazepine, and CNQX were first dissolved in dimethyl sulfoxide (DMSO) at 1000 times the concentrations to be used. Capsaicin, TTX, ruthenium red, and AP5 were first dissolved in distilled water at 1000 times the concentrations to be used, and then these drugs were diluted to the final concentration in Krebs' solution immediately before use. The osmotic pressure of nominally $\mathrm{Ca}^{2+}$-free, high$\mathrm{Mg}^{2+}$ (5 mM) Krebs' solution was adjusted by lowering the $\mathrm{Na}^{+}$ concentration.

Statistical analysis. All numerical data were expressed as mean \pm SEM. Statistical significance was determined as $p<0.05$ using either Kolmogorov-Smirnov test or Student's paired $t$ test. In electrophysiological data, $n$ refers to the number of neurons studied. The membrane potentials were not corrected for the liquid junction potential between the Krebs' and patch-pipette solutions.

\section{Results}

\section{The action of TRPA1 channel activation on excitatory synaptic transmission}

All SG neurons tested exhibited spontaneous EPSCs (sEPSCs) at a holding potential $\left(V_{\mathrm{H}}\right)$ of $-70 \mathrm{mV}$ where no IPSCs were observed (Fig. $1 \mathrm{~A}$ ), because the reversal potential for IPSCs was near $-70 \mathrm{mV}$ (Yoshimura and Nishi, 1995). To identify the action of TRPA1 channel activation on excitatory synaptic transmission, we mainly used AITC, the pungent principal in mustard oil or wasabi, as a selective agonist for TRPA1 in the present study. The sEPSCs recorded from 197 neurons had an average frequency and amplitude of $9.1 \pm 0.2 \mathrm{~Hz}$ (range, $0.3-48.3 \mathrm{~Hz}$ ) and $12.9 \pm 0.4 \mathrm{pA}$ (range, 6.9-48.4 pA), respectively. Superfusing AITC $(100 \mu \mathrm{M})$ for 2 min resulted in a significant increase in the frequency and amplitude of sEPSCs in 129 (65.5\%) of 197 neurons recorded; this action was often accompanied by a slow inward current, as shown in Figure $1 \mathrm{~A}$. When measured for $30 \mathrm{~s}$ under the AITC action, the average increases in sEPSC frequency and amplitude were $201.9 \pm 17.8$ and $65.7 \pm 5.8 \%(n=129)$, respectively (Fig. $1 D)$. Figure $1 B$ demonstrates the effects of AITC $(100 \mu \mathrm{M})$ on the cumulative distributions of the interevent interval and amplitude of sEPSC. AITC increased a proportion of sEPSCs having a significantly shorter interevent interval $(p<0.05)$ and a significantly larger amplitude $(p<0.05)$ when compared with control. Although we did not investigate the histological difference between the AITC-responsive and -nonresponsive SG neurons in the present study, there was no significant difference in electrophysiological characteristics such as resting membrane potential and sEPSC frequency and amplitude. When AITC $(100 \mu \mathrm{M})$ was applied repeatedly at 20 min intervals, it induced a similar increase in sEPSC frequency and amplitude (Fig. $1 C$ ). The average increases in sEPSC frequency and amplitude by the secondary application of AITC were $190.5 \pm 53.5$ and $41.1 \pm 9.0 \%(n=10)$, respectively; these values were not distinct from those by the first application of AITC (179.5 \pm 54.3 and $61.0 \pm 14.8 \%)$ (Fig. $2 C$ ). TRPA1 is also activated by pungent natural compounds in cinnamon oil, ginger, and garlic (Bandell et al., 2004; Bautista et al., 2006). We then tested the effect of CA and allicin, a garlic extract, on excitatory synaptic transmission in those SG neurons in which AITC increased sEPSC frequency and amplitude. As well as AITC, CA is specific to TRPA1 but does not activate TRPV1 and TRPM8 (Bandell et al., 2004). Superfusing CA (100 $\mu \mathrm{M})$ for $2 \mathrm{~min}$ resulted in significant increase in sEPSC frequency and amplitude in all neurons recorded, as shown in Figure $1 C$. The average increases in sEPSC frequency and amplitude by CA were $204.5 \pm$ 21.4 and $87.3 \pm 31.2 \%(n=5)$, respectively (Fig. $1 D)$. Allicin $(100 \mu \mathrm{M})$ also increased sEPSC frequency and amplitude in all neurons recorded (Fig. 1C). The average increases in sEPSC frequency and amplitude by allicin were $139.3 \pm 44.6$ and $80.0 \pm$ $21.4 \%(n=5)$, respectively (Fig. $1 D)$.

A non-NMDA receptor antagonist, CNQX, was tested in those neurons in which AITC increased sEPSC frequency and amplitude. CNQX $(10 \mu \mathrm{M})$ suppressed sEPSCs not only in the control, but also under the action of AITC $(100 \mu \mathrm{M})$ in all three neurons examined (Figs. $2 A, 3 B$ ), indicating AITC caused a robust glutamate release onto SG neurons. To determine whether $\mathrm{Ca}^{2+}$ entry through TRPA1 channels may contribute to the AITC-induced facilitation of sEPSCs, the effect of AITC was examined in the presence of $\mathrm{La}^{3+}(30 \mu \mathrm{M})$, a blocker for voltagegated $\mathrm{Ca}^{2+}$ channels ( $\mathrm{Gu}$ and MacDermott, 1997). The frequency and amplitude of glutamatergic sEPSCs were not affected by $\mathrm{La}^{3+}$ itself $(n=5)$. The frequency and amplitude of sEPSCs in 
A
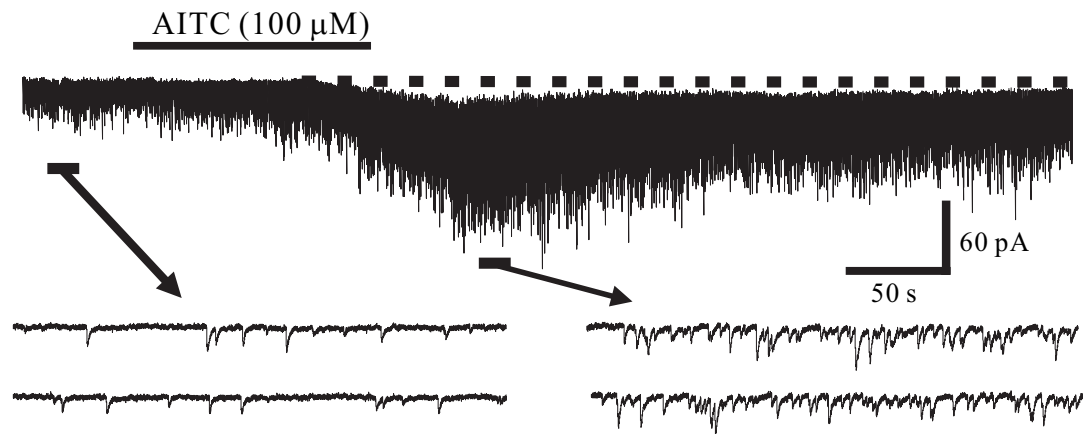

$\mathrm{B}$
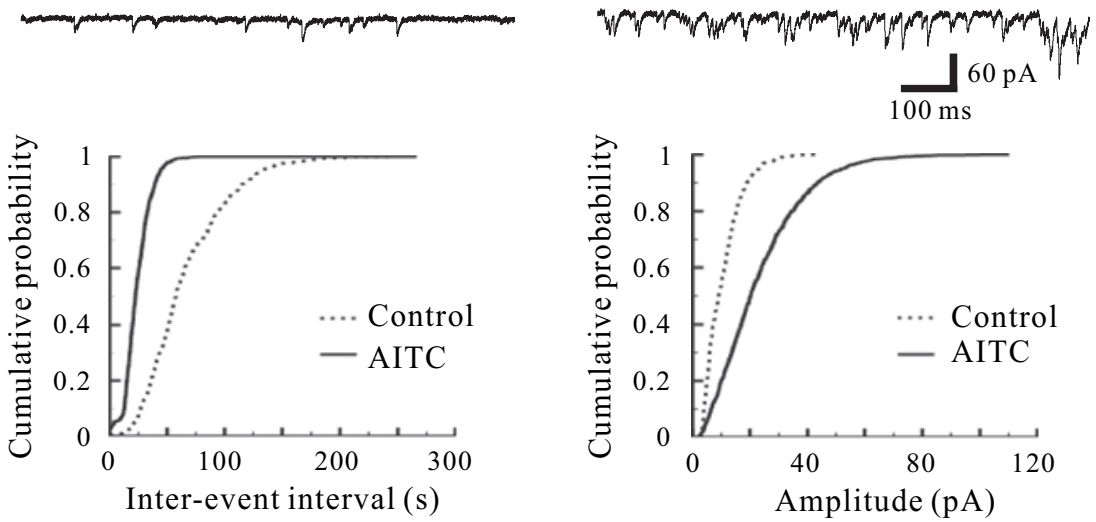

$\mathrm{C}$
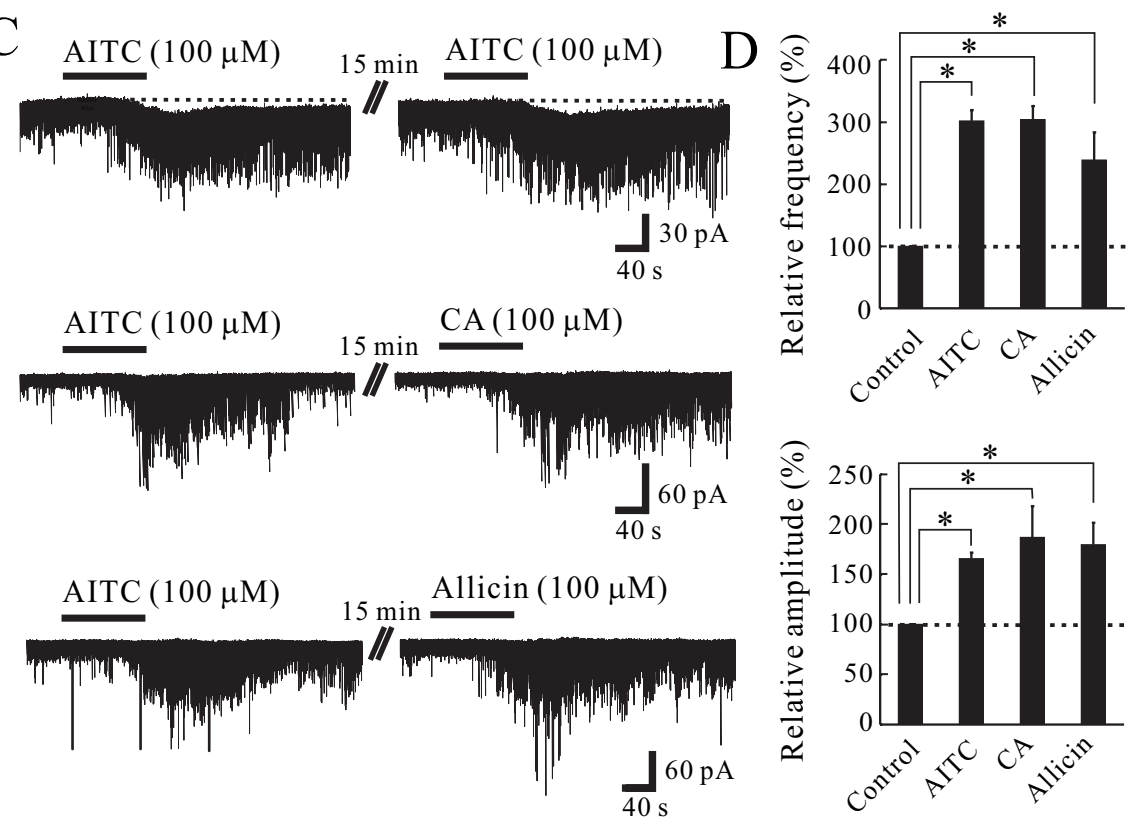

Figure 1. Actions of AITC and related substances on excitatory synaptic transmission in SG neurons. $A$, A continuous chart recording of glutamatergic sEPSCs before and during the action of AITC (100 $\mu \mathrm{m}$; top). Three consecutive traces of sEPSCs are shown in an expanded scale in time, before (bottom left) and during the action of AITC (bottom right). Note a slow inward current that is accompanied by increases in SEPSC frequency and amplitude (top). $\boldsymbol{B}$, Cumulative distributions of the interevent interval (left) and amplitude (right) of sEPSC, before (dotted line) and during (continuous line) the action of AITC. AITC shifted the interevent interval and amplitude to a shorter and a larger one, respectively ( $p<0.05$; Kolmogorov-Smirnov test). Data in $\boldsymbol{A}$ and $\boldsymbol{B}$ were obtained from the same neuron. $\boldsymbol{C}$, When AITC $(100 \mu \mathrm{m})$ was applied repeatedly at 20 min intervals, it produced similar increases in sEPSC frequency and amplitude and induced an inward current having a similar amplitude (top). CA (100 $\mu \mathrm{m}$ ) mostly increased sEPSC frequency and amplitude in a neuron in which AITC increased sEPSC frequency and amplitude (middle). Allicin $(100 \mu \mathrm{m})$ also increased sEPSC frequency and amplitude in a neuron in which AITC increased sEPSC frequency and amplitude (bottom). D, Summary of sEPSC frequency (top) and amplitude (bottom) under the action of AITC $(n=129), C A(n=5)$, and allicin $(n=5)$, relative to those in the control. Vertical lines accompanied by bars show SEM. Statistical significance between data shown by bars is indicated by an asterisk; ${ }^{*} p<0.05$. The holding potential $\left(V_{H}\right)$ used was $-70 \mathrm{mV}$. the presence of $\mathrm{La}^{3+}$ were $93.7 \pm 9.0 \%$ and $102.6 \pm 4.7 \%(n=5)$ of control, respectively; these values were not significantly different from $100 \%(p>0.05)$. Even in the presence of $\mathrm{La}^{3+}$, AITC (100 $\mu \mathrm{M})$ primarily increased sEPSC frequency and amplitude. The average increases in sEPSC frequency and amplitude were $101.3 \pm 34.6$ and $44.5 \pm 14.2 \%(n=5)$ (Fig. 2C), respectively; these values were significantly larger than $0 \%(p<0.05)$ (Fig. 2C). Although $\mathrm{La}^{3+}$ also inhibits a number of TRP channels (Kamouchi et al., 1999; Inoue et al., 2001), the action of AITC on sEPSC frequency and amplitude was not affected by $\mathrm{La}^{3+}$. The average increases in sEPSC frequency and amplitude by the application of AITC in the presence of $\mathrm{La}^{3+}$ were not significantly different from those in the absence of $\mathrm{La}^{3+}$. Next, we examined whether the AITC-induced increases in sEPSC frequency and amplitude are dependent on extracellular $\mathrm{Ca}^{2+}$. The frequency and amplitude of sEPSCs in $\mathrm{a} \mathrm{Ca}^{2+}$-free bath solution were $65.3 \pm 6.5$ and $91.4 \pm 6.6 \%(n=9)$ of control, respectively. The frequency of sEPSCs in a $\mathrm{Ca}^{2+}$-free bath solution was significantly smaller than that in a normal Krebs' solution $(p<0.05)$, whereas sEPSC amplitude was not significantly affected in a $\mathrm{Ca}^{2+}$. free bath solution $(p>0.05)$. Under this condition, superfusing AITC $(100 \mu \mathrm{M}) \mathrm{did}$ not significantly increase sEPSC frequency and amplitude (Fig. 2B). The frequency and amplitude of sEPSCs by the application of AITC in a $\mathrm{Ca}^{2+}$-free bath solution were $119.8 \pm 17.0$ and $112.0 \pm 10.4 \%(n=$ 8) (Fig. 2C) of control, respectively; these values were not significantly distinct from $100 \%(p>0.05)$. We further investigated that AITC-sensitive terminals were monosynaptically connected with SG neurons. This was done by determining the effects of AITC $(100 \mu \mathrm{M})$ on miniature EPSCs (mEPSCs) in the presence of TTX (0.5 $\mu \mathrm{M})$. As seen in Figure 2D, AITC markedly increased both mEPSC frequency and amplitude in the presence of TTX. The average increases in mEPSC frequency and amplitude were $147.4 \pm 64.5$ and $35.0 \pm$ $12.2 \%(n=13)$, respectively; these values were not significantly different from those in the absence of TTX. Figure $2 E$ demonstrates the effects of AITC $(100 \mu \mathrm{M})$ on the cumulative distributions of the interevent interval and amplitude of mEPSC. AITC increased a proportion of mEPSCs having a significantly shorter interevent interval $(p<0.05)$ and a significantly larger amplitude $(p<0.05)$ when compared with control. In 11 neurons in which AITC significantly increased mEPSC frequency, we 
constructed an amplitude histogram. Figure $2 \mathrm{~F}$ shows a typical result of a neuron exhibiting a large increase in MEPSC frequency and amplitude by the application of AITC. Despite the change in the form of distribution, the modal peak of the distribution at $\sim 10 \mathrm{pA}$ was not affected by AITC; there was not the appearance of a discrete high-amplitude population of mEPSCs.

AITC generated an inward current at $-70 \mathrm{mV}$ in 75 (38.1\%) of 197 neurons examined (Fig. $1 A, C$ ). The average peak amplitude of the AITC-induced inward current was $12.6 \pm 0.8 \mathrm{pA}(n=75)$. The inward current varied in duration in a range of 113-703 s with an average of $279.0 \pm 14.1 \mathrm{~s}(n=75)$. As well as AITC, superfusing CA $(100 \mu \mathrm{M})$ for 2 min produced an inward current in 3 of 6 neurons examined (data not shown). The average peak amplitude of the CA-induced inward current was $6.7 \pm 1.7 \mathrm{pA}(n=3)$. Allicin also induced an inward current in 4 of 6 neurons recorded (data not shown). The average peak amplitude of the allicininduced inward current was $11.3 \pm 1.7 \mathrm{pA}$ $(n=4)$. When AITC $(100 \mu \mathrm{M})$ was applied repeatedly at $20 \mathrm{~min}$ intervals, it induced an inward current having a similar amplitude (Fig. 1C). The average peak amplitude of the inward current by the secondary application of AITC was $11.1 \pm 2.3 \mathrm{pA}$ $(n=7)$, and it was not significantly different from that by the first application of AITC $(13.3 \pm 2.4 \mathrm{pA} ; p>0.05)$ (Fig. $3 E$ ). The AITC-induced inward current was resistant to TTX $(0.5 \mu \mathrm{M})$ (Fig. $3 A)$. The average peak amplitude of the AITCinduced inward current in the presence of TTX was $10.2 \pm 1.9 \mathrm{pA}(n=6)$; this value was not significantly distinct from that in the absence of TTX $(13.2 \pm 3.5 \mathrm{pA} ; p>$ 0.05 ) (Fig. 3E). However, the AITCinduced inward current was significantly suppressed in a $\mathrm{Ca}^{2+}$-free bath solution (Fig. 2B). The average peak amplitude of the AITC-induced inward current in a $\mathrm{Ca}^{2+}$-free bath solution was $5.5 \pm 1.9 \mathrm{pA}$ $(n=6)$; this value was significantly distinct from that in a normal Krebs' solution (13.3 $\pm 3.1 \mathrm{pA} ; p<0.05)$. Moreover, AITC still produced an inward current in the presence of CNQX $(10 \mu \mathrm{M})$, whereas CNQX suppressed the AITC-induced increase in sEPSC frequency (Fig. $3 B$; see also Fig. $2 A$ ). The average peak amplitude of the AITC-induced inward current in the presence of CNQX was $13.4 \pm 5.1 \mathrm{pA}(n=$ $5)$; this value was not distinct from that in the absence of CNQX (11.8 $\pm 3.5 \mathrm{pA} ; p>$ 0.05 ) (Fig. 3E). In contrast, the AITCinduced inward current was blocked in the
A

B
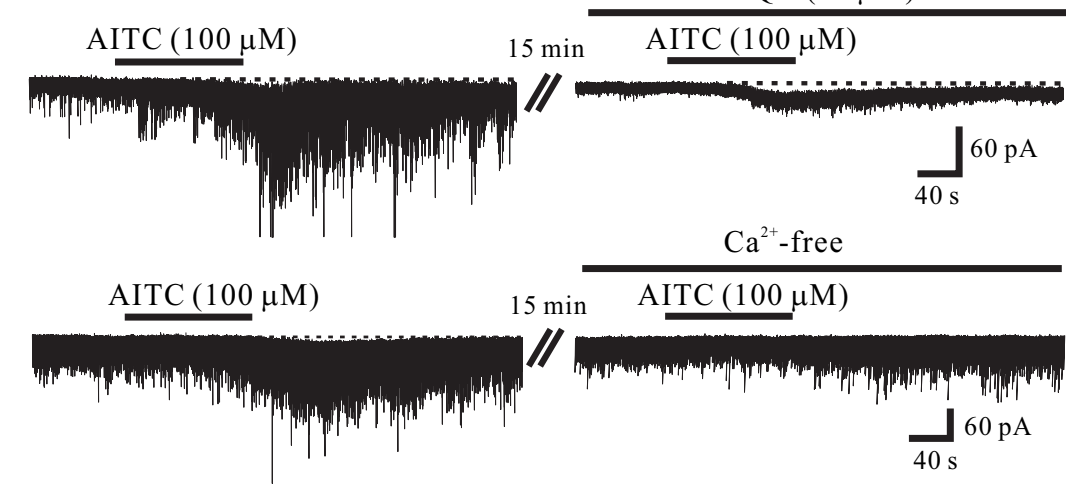

C

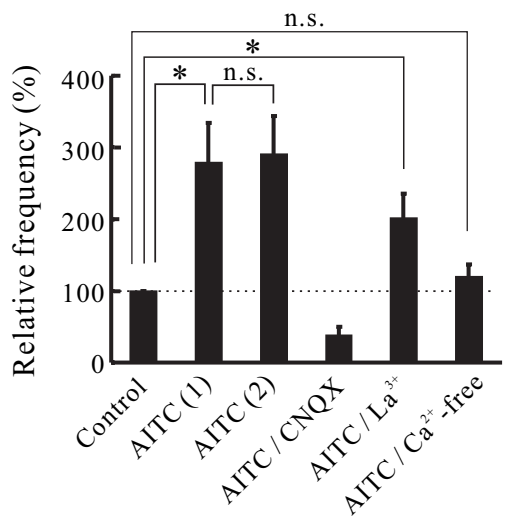

D
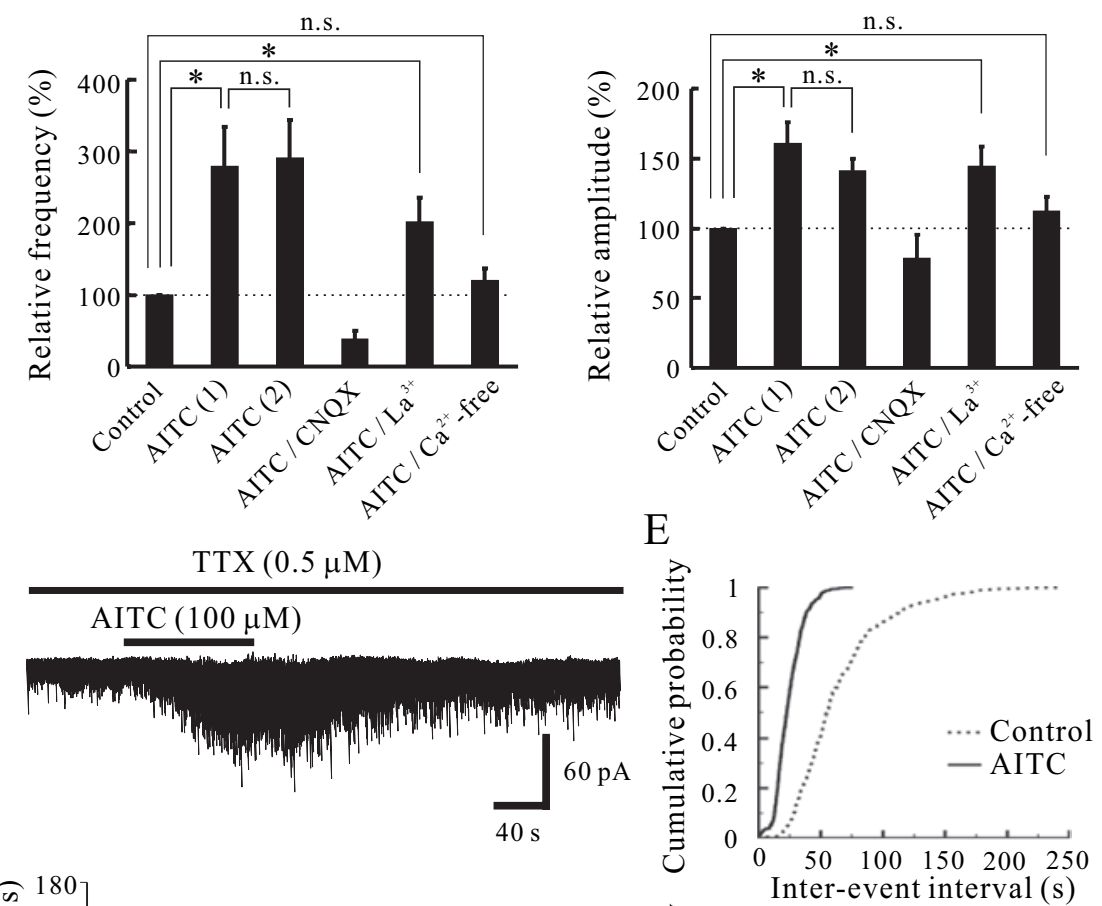

$\mathrm{F}$
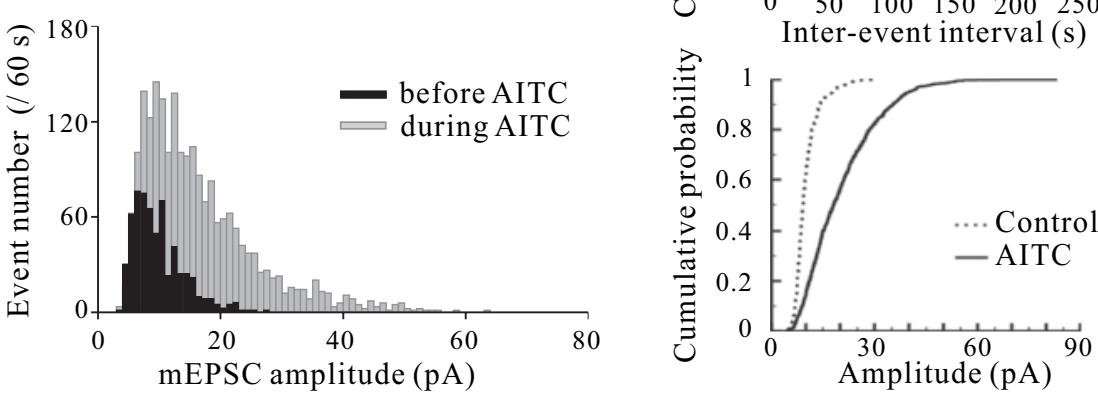

Figure 2. Characterization of the AITC-induced increases in sEPSC frequency and amplitude. $A$, Action of AITC (100 $\mu \mathrm{M})$ on sEPSCs in the absence (left) and presence (right) of CNQX (10 $\mu \mathrm{M})$. CNQX blocked sEPSCs not only in the absence of AITC but also under its action (right). $\boldsymbol{B}$, Action of AITC on sEPSCs in normal Krebs' (left) and $\mathbf{C a}^{2+}$-free solution (right). The AITC-induced increases in sEPSC frequency and amplitude were significantly reduced in extent in a $\mathrm{Ca}^{2+}$-free solution (right). $C$, Summary of sEPSC frequency (left) and amplitude (right) under the first [AITC (1), $n=10]$ and second application of AITC [AITC (2), $n=10]$, under the action of AITC in the presence of CNQX $(n=3) \operatorname{or~La}^{3+}(n=5)$, and the action of AITC in Ca ${ }^{2+}$-free solution $(n=8)$, relative to those in the control. Vertical lines accompanied by bars show SEM. Statistical significance between data shown by bars is indicated by an asterisk; ${ }^{*} p<0.05$. n.S., Not significant. $\boldsymbol{D}$, A continuous chart recording of glutamatergic miniature EPSCS (mEPSCs) in the presence of TTX $(0.5 \mu \mathrm{m})$ before and under the action of AITC (100 $\mu \mathrm{m})$. $\boldsymbol{E}$, Cumulative distributions of the interevent interval (top) and amplitude (bottom) of mEPSCs, before (dotted line) and during (continuous line) the action of AITC. AITC shifted the interevent interval and amplitude to a shorter and a larger one, respectively ( $p<0.05$; Kolmogorov-Smirnov test). $\boldsymbol{F}$, Distributions of sEPSC amplitude before and during (filled bar and gray bar, respectively) the action of AITC. The bin width is 1 pA. $V_{H}=-70 \mathrm{mV}$. 
A

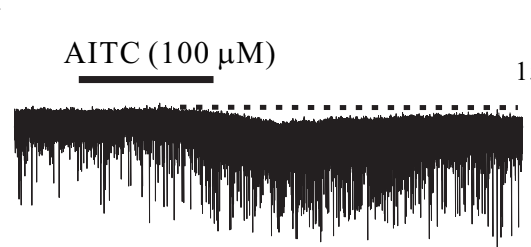

B

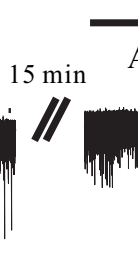

$\operatorname{TTX}(0.5 \mu \mathrm{M})$

\section{$\operatorname{AITC}(100 \mu \mathrm{M})$}

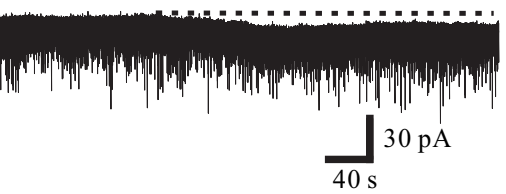

CNQX $(10 \mu \mathrm{M})$

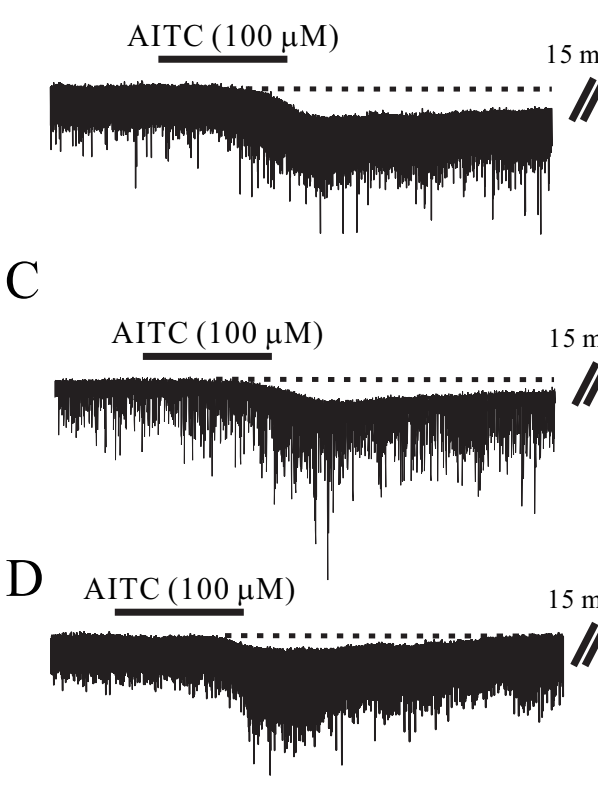

$\mathrm{E}$

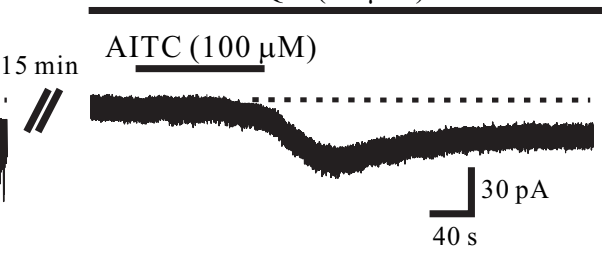

CNQX $(10 \mu \mathrm{M})+\mathrm{AP} 5(50 \mu \mathrm{M})$

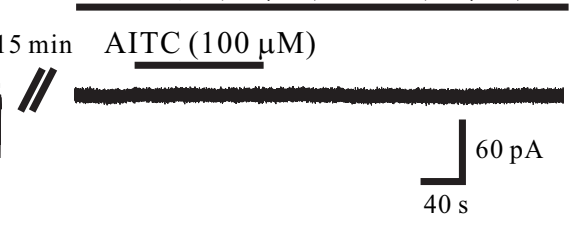

15 min Capsaicin $(2 \mu \mathrm{M})+\operatorname{AITC}(100 \mu \mathrm{M})$

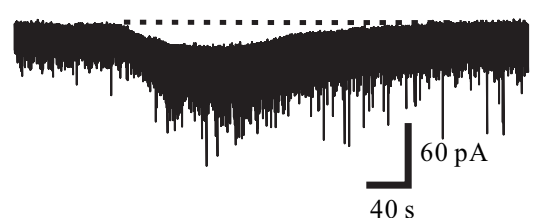

*

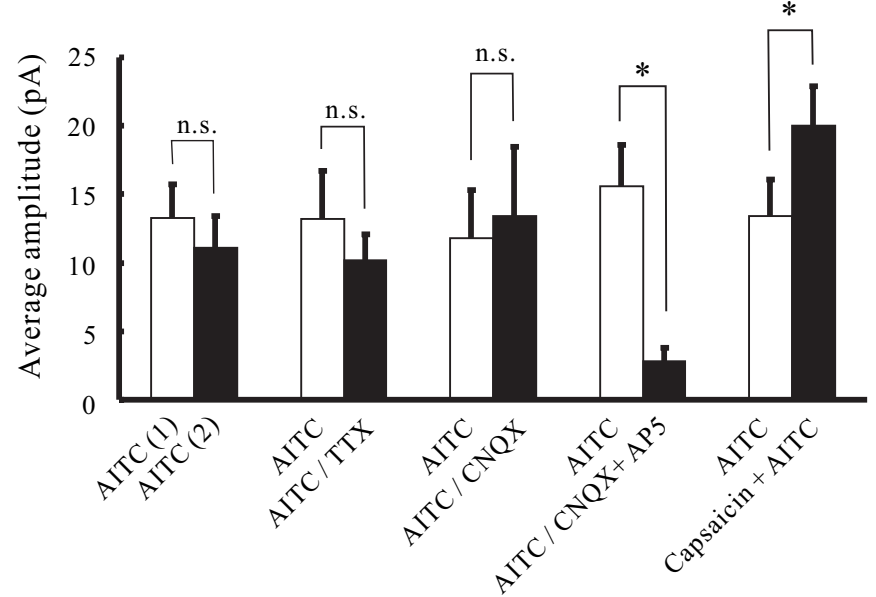

Figure 3. AITC induces a slow inward current in SG neurons. $A$, Action of AITC on the membrane holding current in the absence (left) and presence (right) of TTX $(0.5 \mu \mathrm{M})$. The amplitude of the AITC-induced inward current did not change in the presence of TTX. $\boldsymbol{B}$, Action of AITC on the membrane holding current in the absence (left) and presence (right) of CNQX (10 $\mu \mathrm{m}$ ). In the presence of CNQX, AITC induced an inward current without any decrease in amplitude. C, Action of AITC on the membrane holding current in the absence (left) and presence (right) of CNQX (10 $\mu \mathrm{M})$ and AP5 $(50 \mu \mathrm{m})$. The addition of AP5 to CNQX significantly suppressed the AITC-induced inward current. D, When capsaicin $(2 \mu \mathrm{M})$ was applied together with AITC (100 $\mu \mathrm{m})$, the amplitude of the inward current was larger than that by AITC only. $\boldsymbol{E}$, The average amplitudes of the inward currents induced by the first [AITC (1), $n=7$ ] and second application of AITC in control [AITC (2), $n=7$ ], and AITC in the absence and presence of TTX ( $n=6)$, AITC in the absence and presence of $\mathrm{CNQX}(n=5)$, AITC in the absence and presence of CNQX and AP5 $(n=5)$, and also by AITC $(n=5)$ only and both AITC and capsaicin $(n=5) \cdot V_{\mathrm{H}}=-70 \mathrm{mV}$. than that in the absence of CNQX and AP5 $(15.6 \pm 3.0 \mathrm{pA} ; p<0.05)$ (Fig. $3 E)$. It was recently reported that TRPA1 is coexpressed with noxious heat-sensing TRPV1 in soma of small-sized primary sensory neurons (Story et al., 2003; Kobayashi et al., 2005). Capsaicin (2 $\mu \mathrm{M})$, a selective TRPV1 agonist, was applied together with AITC $(100 \mu \mathrm{M})$ in those neurons in which AITC $(100 \mu \mathrm{M})$ induced an inward current (Fig. 3D). The average peak amplitude of the inward current by the application of capsaicin and AITC was $20.0 \pm 2.9 \mathrm{pA}(n=5)$, values being significantly larger than that $(13.4 \pm 2.7 \mathrm{pA})$ by the first application of AITC only $(p<0.05)$ (Fig. 3E).

The AITC-induced increases in sEPSC frequency and amplitude were suppressed by a TRP channel antagonist, ruthenium red $(300 \mu \mathrm{M})$ (Fig. 4A). The AITCinduced increases in sEPSC frequency and amplitude in the presence of ruthenium red averaged to be $3.0 \pm 10.6$ and $1.9 \pm$ $4.3 \%(n=5)$, respectively; these values were significantly smaller than those in the absence of ruthenium red $(p<0.05)$ (Fig. $4 D)$. The AITC-induced inward current was also reduced in amplitude by ruthenium red $(n=3)$. However, the AITCinduced increases in sEPSC frequency and amplitude were not affected by a TRPV1 channel antagonist, capsazepine $(10 \mu \mathrm{M})$, at all (Fig. 4B). The AITC-induced increases in sEPSC frequency and amplitude in the presence of capsazepine averaged to be $168.4 \pm 50.4$ and $105.7 \pm 36.7 \%(n=$ 5 ), respectively; these values were not distinct from those in the absence of capsazepine $(p>0.05)$ (Fig. $4 D)$. Moreover, we examined whether previous treatment with capsaicin could inhibit the subsequent AITC-induced increases in sEPSC frequency and amplitude. Superfusing capsaicin $(2 \mu \mathrm{M})$ for 2 min resulted in a large increase in the frequency and amplitude of sEPSCs in all seven neurons recorded; this action was accompanied by a slow inward current (Fig. 4C). When $\operatorname{AITC}(100 \mu \mathrm{M})$ was applied at $20 \mathrm{~min}$ after washout of capsaicin, it induced a significant increase in sEPSC frequency and amplitude (Fig. 4C). The average increases in sEPSC frequency and amplitude by the application of AITC $(100 \mu \mathrm{M})$ were $173.8 \pm$ 61.8 and $44.5 \pm 9.8 \%(n=5)$, respectively; these values were not distinct from those without the pretreatment of capsaicin (Fig. 4D). presence of AP5 $(50 \mu \mathrm{M})$, an NMDA receptor antagonist, together with CNQX $(10 \mu \mathrm{M})$ (Fig. 3C). The average peak amplitude of the AITC-induced inward current in the presence of CNQX and AP5 was $2.8 \pm 1.1 \mathrm{pA}(n=5)$; this value was smaller
The action of TRPA1 activation on inhibitory synaptic transmission

Spontaneous IPSCs (sIPSCs) were observed in all SG neurons recorded at a $V_{\mathrm{H}}$ of $0 \mathrm{mV}$, at which EPSCs were invisible because 
of the reversal potential for EPSCs to be close to $0 \mathrm{mV}$. The sIPSCs recorded from 11 neurons had an average frequency and amplitude of $6.8 \pm 1.4 \mathrm{~Hz}$ (range, $0.5-14.3$ $\mathrm{Hz}$ ) and $16.6 \pm 1.3 \mathrm{pA}$ (range, 10.1-23.0 pA), respectively. Superfusing AITC (100 $\mu \mathrm{M})$ remarkably increased sIPSC frequency and amplitude in all 11 neurons recorded (Fig. 5A). Figure $5 B$ demonstrates the effects of AITC $(100 \mu \mathrm{M})$ on cumulative distributions of the interevent interval and amplitude of sIPSC. AITC increased a proportion of sIPSCs having a significantly shorter interevent interval $(p<0.05)$ and a significantly larger amplitude $(p<0.05)$ when compared with control. When measured for $30 \mathrm{~s}$ under the AITC action, the average increases in sIPSC frequency and amplitude were $117.0 \pm 29.5$ and $42.5 \pm 9.8 \%(n=11)$, respectively. However, when AITC (100 $\mu \mathrm{M})$ was perfused in the presence of TTX $(0.5 \mu \mathrm{M})$ in neurons in which AITC mostly increased sIPSC frequency and amplitude $(n=7)$, mIPSC frequency and amplitude were unaltered $(94.8 \pm 2.7$ and $97.6 \pm$ $2.9 \%$ of control, respectively) (Fig. $5 C$ ). Moreover, AITC $(100 \mu \mathrm{M})$ did not affect sIPSC frequency and amplitude in a mixture of CNQX $(10 \mu \mathrm{M})$ and AP5 $(50 \mu \mathrm{M})$ (Fig. 5D). The average sIPSC frequency and amplitude in a mixture of CNQX and AP5 were $113.6 \pm 6.1$ and $98.8 \pm 3.3 \%$ $(n=4)$ of control, respectively.

\section{Discussion}

In the present study, we have examined the effects of AITC, an agonist for TRPA1 channel, on synaptic transmission in SG neurons of spinal cord slices. AITC enhances the frequency and amplitude of glutamatergic sEPSC in $\sim 70 \%$ of neurons examined and generates an inward current in $\sim 40 \%$ of neurons recorded. The AITCinduced increase in sEPSC frequency and amplitude is resistant to TTX, and thus this AITC action appears to be attributable to a direct action of TRPA1 activation. AITC also enhances sIPSC frequency and amplitude, but not in the presence of TTX or in a mixture of CNQX and AP5, suggesting that the AITC-sensitive pathway recruits polysynaptic inhibitory inputs to SG neurons. In the present study, we first demonstrated the TRPA1-mediated modulation of synaptic transmission in the CNS.

TRPA1 is present on peptidergic TRPV1-expressing primary sensory neurons (Story et al., 2003; Kobayashi et al., 2005), and it may be involved in a variety of sensory processes, including cold transduction, mechanosensation, inflammatory hyperalgesia, and neuropathic pain. In fact, CA, an agonist for TRPA1, can evoke spontaneous pain and induce mechanical hyperalgesia and cold hypoalgesia when it is delivered to the forearm skin of hu-

A

B

$\mathrm{C}$
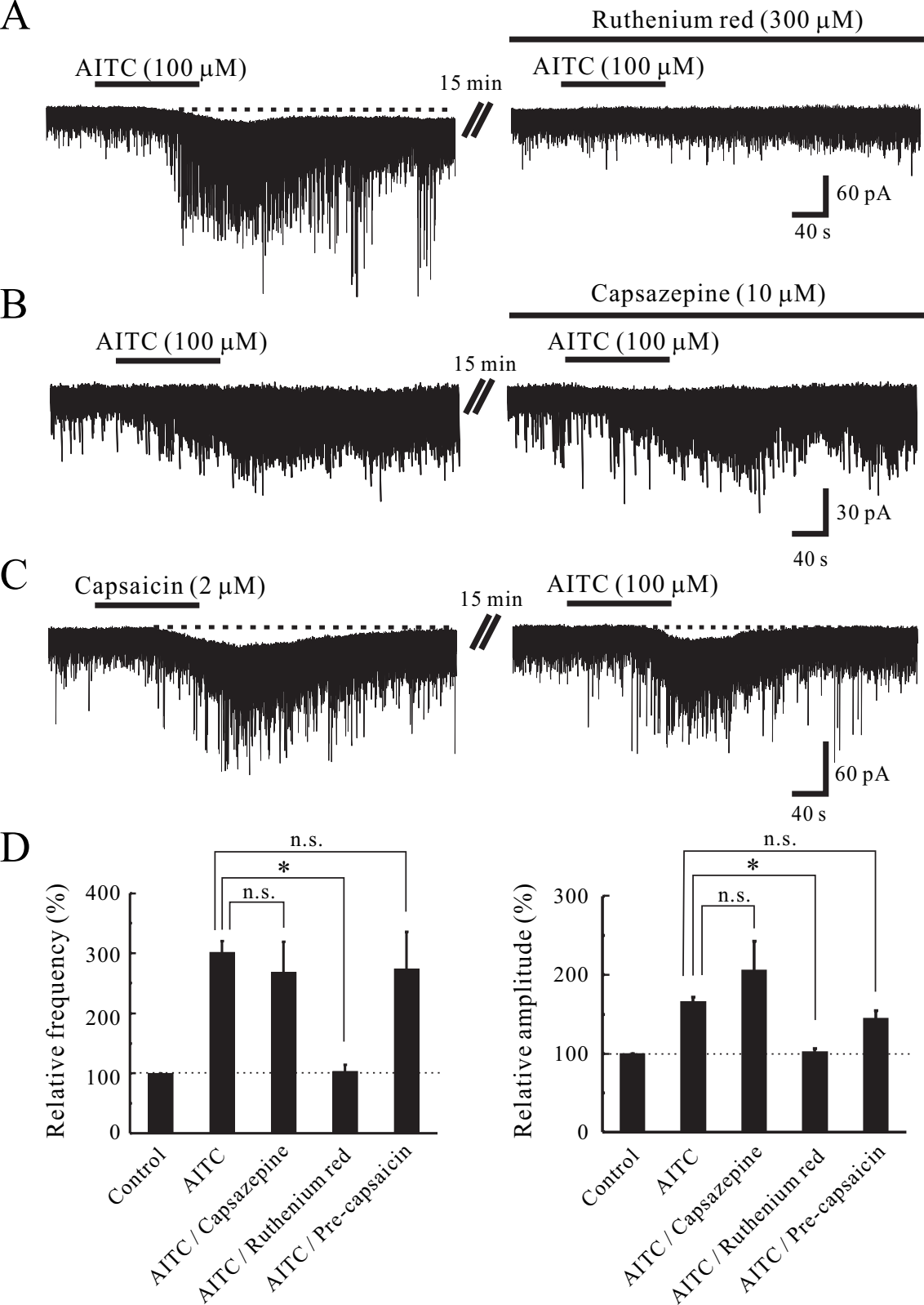

Figure 4. Effects of TRP agonists and antagonists on sEPSC frequency and amplitude. A, Action of AITC (100 $\mu \mathrm{M})$ on sEPSCs in the absence (left) and presence (right) of ruthenium red $(300 \mu \mathrm{m})$. Ruthenium red significantly suppressed the AITC-induced increase in sEPSC frequency and amplitude. B, Action of AITC (100 $\mu \mathrm{m})$ on sEPSCs in the absence (left) and presence (right) of capsazepine $(10 \mu \mathrm{M})$. Capsazepine did not affect the AITC-induced increases in sEPSC frequency and amplitude. C, Capsaicin (2 $\mu \mathrm{M})$ mostly increased sEPSC frequency and amplitude in a neuron. When AITC (100 $\mu \mathrm{M})$ was applied at 20 min after washout of capsaicin, it still increased sEPSC frequency and amplitude and produced an inward current. $D$, Summary of sEPSC frequency (left) and amplitude (right) under the action of AITC $(n=129)$, AITC in the presence of capsazepine $(n=5)$, AITC in the presence of ruthenium red $(n=5)$, and AITC with the pretreatment of capsaicin $(n=5)$, relative to those in the control. Vertical lines accompanied by bars show SEM. Statistical significance between data shown by bars is indicated by an asterisk; ${ }^{*} p<0.05$. n.S., Not significant. $V_{\mathrm{H}}=-70 \mathrm{mV}$.

man volunteers (Namer et al., 2005). Moreover, TRPA1 is upregulated in primary sensory neurons after peripheral inflammation and nerve injury, and inflammation- and nerve injuryinduced cold hyperalgesia is mediated by TRPA1 but not by TRPM8 (Obata et al., 2005). However, there is no loss of either auditory function or mechano- and thermosensation in TRPA1deficient mice (Bautista et al., 2006). However, another study using TRPA1-deficient mice has shown that TRPA1 is apparently not essential for hair cell transduction but contributes to the 
A

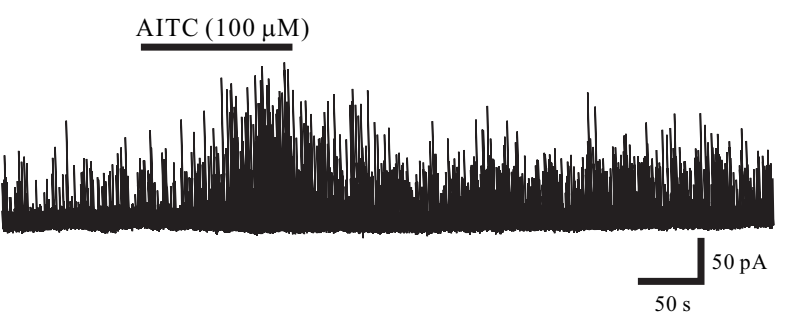

B
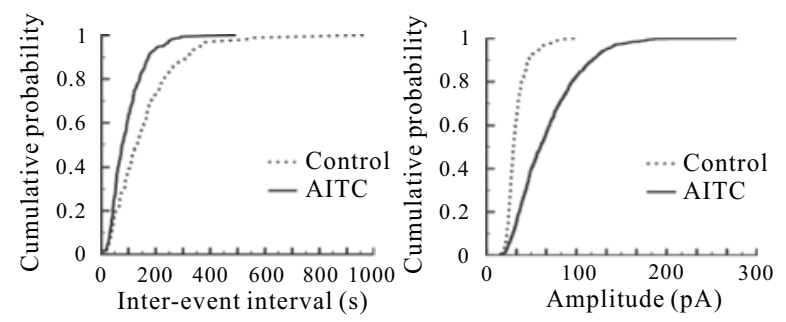

C
$\operatorname{TTX}(0.5 \mu \mathrm{M})$

$\operatorname{AITC}(100 \mu \mathrm{M})$

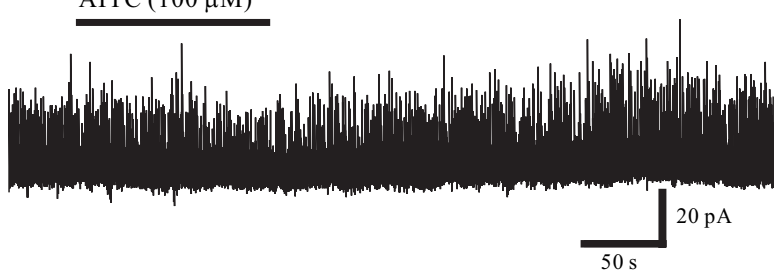

$\mathrm{D}$

CNQX $(10 \mu \mathrm{M})+\operatorname{AP} 5(50 \mu \mathrm{M})$

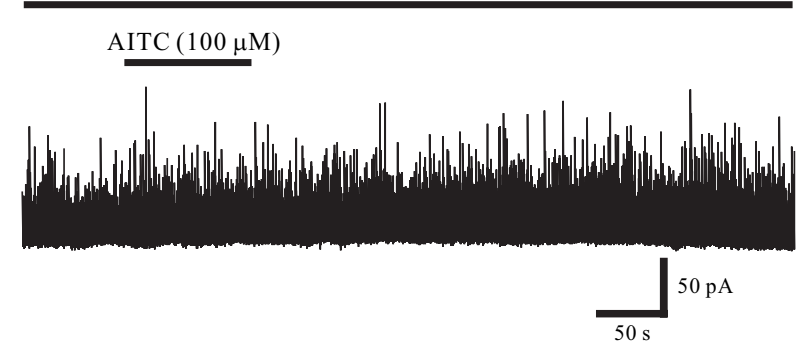

Figure 5. Action of AlTC on inhibitory synaptic transmission in SG neurons. $A$, A continuous chart recording of SIPSCs before and during the action of AITC $(100 \mu \mathrm{M})$. B, Cumulative distributions of the interevent interval (left) and amplitude (right) of sIPSCS, before (dotted line) and during the action of AITC (continuous line). AITC shifted the interevent interval and amplitude to a shorter and a larger one, respectively ( $p<0.05$; Kolmogorov-Smirnov test). C, A continuous chart recording of mIPSCs before and during the action of AITC $(100 \mu \mathrm{M})$ in the presence of TTX $(0.5 \mu \mathrm{M})$. TTX abolished the AITC-induced increases in SIPSC frequency and amplitude. D, A continuous chart recording of sIPSCs before and during the action of AITC in a mixture of CNQX $(10 \mu \mathrm{M})$ and AP5 $(50 \mu \mathrm{M})$. The AITC-induced increase in sIPSC frequency and amplitude was attenuated in the presence of the drugs. $V_{H}=0 \mathrm{mV}$.

transduction of cold, mechanical, and chemical stimuli in primary sensory neurons (Kwan et al., 2006). Therefore, the peripheral role of TRPA1 in cold and mechanical transduction is still controversial.

The central terminals derived from primary afferent fibers make the first sensory synapses with spinal dorsal horn neurons. At these synapses, glutamate is used as a fast excitatory neurotransmitter to convey sensory signals from the periphery (Yoshimura and Jessell, 1990). A number of channels are expressed at the central terminals of primary afferent fibers, and these channels play important roles in synaptic modulation of neurotransmitter release onto spinal dorsal horn neurons. For example, TRPV1 and P2X are expressed at the central terminals of primary afferent fibers and their presynaptic activation facilitates glutamate release (Yang et al., 1998; Nakatsuka and Gu, 2001; Nakatsuka et al., 2002). As well as TRPV1 and P2X, TRPA1 is a ligandgated nonselective cation channel permeable to $\mathrm{Ca}^{2+}$, and coexpressed with TRPV1 but not TRPM8 in nociceptive primary sensory neurons (Story et al., 2003; Kobayashi et al., 2005). However, it has never been addressed whether TRPA1 locates at the central terminals of primary afferent fibers and whether their activation modulates synaptic transmission in the spinal dorsal horn. The present study is the first report showing that selective TRPA1 agonists such as AITC and CA markedly enhance excitatory synaptic transmission. The AITC-induced increases in sEPSC frequency and amplitude were also observed in the presence of $\mathrm{La}^{3+}$. Furthermore, AITC increased the frequency of mEPSCs in the presence of TTX; this AITC action was suppressed in a $\mathrm{Ca}^{2+}$-free solution. These results indicate that AITC enhances the glutamate release by direct $\mathrm{Ca}^{2+}$ entry through TRPA1 channels in the nerve terminals. Because TRPA1 mRNA has never been detected in the spinal cord, this facilitation of glutamate release appears to be caused by a direct action of AITC on TRPA1 at the central terminals of primary afferent fibers which make synapses with SG neurons. AITC also increased the amplitude of mEPSCs in the presence of TTX. If MEPSC amplitude is mediated by postsynaptic non-NMDA receptor, all of the event amplitudes would be increased equally. However, in the distribution of mEPSC amplitude, the modal peak of $\sim 10 \mathrm{pA}$ was not affected by AITC in the present study (see Fig. $2 F$ ). Although the possibility that the large amplitude of mEPSCs provoked by AITC is caused by the activation of postsynaptic TRPA1 cannot be ruled out, the large amplitude of mEPSCs induced by AITC may result from highly synchronized multivesicular release of glutamate, as shown in P2X activation at glutamatergic terminals in the brainstem (Shigetomi and Kato, 2004). Superfusing capsaicin resulted in enhancing excitatory synaptic transmission on those SG neurons in which AITC increased sEPSC frequency and amplitude. This result suggests that TRPA1 is coexpressed with TRPV1 at the central terminals of primary afferent fibers, consistent with the previous studies using in situ hybridization in soma of primary sensory neurons (Story et al., 2003; Kobayashi et al., 2005).

The present study also demonstrated that AITC produces an inward current in SG neurons. The AITC-induced inward current was resistant to TTX and did not change in the presence of CNQX, although the AITC-induced facilitation of glutamate release disappeared. However, the AITC-induced inward current was blocked in the presence of CNQX and AP5. These results suggest that the AITC-induced inward current is mediated by the activation of postsynaptic NMDA receptors in SG neurons. Consistent with the finding, several subtypes of NMDA receptors are found in SG neurons (Tölle et al., 1993). The NMDA receptormediated postsynaptic current can be evoked by the application of NMDA and by focal or dorsal root stimulation at a $V_{\mathrm{H}}$ of -70 $\mathrm{mV}$ (Yajiri et al., 1997). Because the AITC-induced inward current is unaffected by TTX, but blocked in a $\mathrm{Ca}^{2+}$-free bath solution, it is attributable to the sustained glutamate release from TRPA1-expressing presynaptic terminals. Capsaicin also generates an inward current in SG neurons, but the current cannot be elicited by the second application of capsaicin (Yang et al., 1998), a result different from that of AITC. Although it remains unclear what kinds of neurotransmitters mediate the capsaicin-induced inward current, the capsaicin-induced inward current is not affected by AP5 (Yang et al., 2000). Furthermore, the average peak amplitude of the inward current by the application of capsaicin 


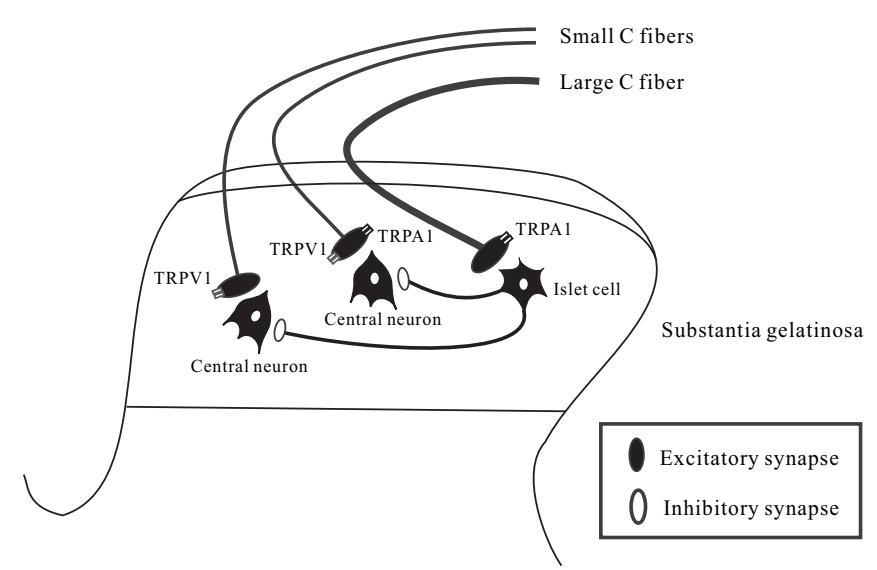

Figure 6. Schematic illustration of possible sites on which AITC acts in the SG. Schematic illustration of a proposed synaptic convergence of distinct TRPA1-sensitive sensory pathways onto $S G$ neurons. Both central neurons and islet cells in the $S G$ receive monosynaptic excitatory input from different primary afferent fibers. Central neurons receive an input from primary afferent fibers, which are sensitive to both TRPA1 and TRPV1, or TRPV1 only, whereas islet cells receive an input from TRPA1-sensitive and TRPV1-insensitive primary afferent fibers. The islet cell is an inhibitory interneuron and presynaptic to a central neuron.

and AITC was significantly larger than that by the first application of AITC only. These results suggest that distinct neurotransmitters may be involved in the AITC- and capsaicin-induced inward currents.

The present study also demonstrated that AITC remarkably increases GABAergic and/or glycinergic sIPSC frequency and amplitude in SG neurons. This AITC-induced enhancement of inhibitory synaptic transmission was abolished in the presence of TTX as well as in a mixture of CNQX and AP5. Therefore, TRPA1 is suggested to be localized not only at presynaptic terminals on SG neurons, but also in primary afferent fibers innervating onto spinal inhibitory interneurons which make synapses with SG neurons (Fig. 6). Consistent with this idea, the recent study using double patch-clamp recordings from SG neurons has revealed that the inhibitory connections are present between two kinds of SG neurons (Lu and Perl, 2003). Both of the presynaptic islet cell and postsynaptic central neuron receive monosynaptic inputs from different C-fibers ( $\mathrm{Lu}$ and Perl, 2003). The input to the presynaptic islet cell is from larger-diameter, more rapidly conducting C-fibers than those projecting to the postsynaptic central neuron. In contrast to AITC, capsaicin does not affect inhibitory synaptic transmission in SG neurons (Yang et al., 1998). Therefore, the expression of TRPA1 does not appear to fully overlap with that of TRPV1 at the central terminals of primary afferent fibers.

The present finding that TRPA1 is present at central terminals of primary afferent fibers and is involved in the modulation of synaptic transmission in the spinal dorsal horn has raised another issue about endogenous substances activating presynaptic TRPA1. Because several endogenous ligands for TRPV1 have been found recently, endogenous ligands for TRPA1 may be present in the CNS in addition to its natural irritants such as mustard oil. Recent findings have demonstrated that intracellular $\mathrm{Ca}^{2+}$ is an important endogenous ligand of TRPA1 (Jordt et al., 2004; Zurborg et al., 2007). Because a number of $\mathrm{Ca}^{2+}$ permeable ionotropic receptors, such as NMDA and P2X receptors, are expressed in the central terminal of primary afferents innervating onto SG neurons, the increase in intracellular $\mathrm{Ca}^{2+}$ by the activation of these receptors may directly activate TRPA1. Inflammatory peptide bradykinin is another of possible endoge- nous ligands, because TRPA1 can be activated by its action on phospholipase C signaling pathways (Bandell et al., 2004; Bautista et al., 2006). Although bradykinin is considered to be a peripherally acting mediator, bradykinin production in the spinal cord is induced by peripheral inflammation (Wang et al., 2005). Furthermore, it was demonstrated that bradykinin also increases glutamate release from central terminals of primary afferents onto SG neurons (Wang et al., 2005). Additional investigations will be required to clarify whether TRPA1 is involved in bradykinin-mediated enhancement in glutamatergic excitatory transmission in SG neurons. The potentiation of excitatory synaptic transmission by the activation of presynaptic TRPA1 may have important implications in pathological pain sensations such as cold hyperalgesia or allodynia. Therefore, TRPA1 in the spinal dorsal horn may be a potential therapeutic target for the treatment of pathological pain sensations.

\section{References}

Bandell M, Story GM, Hwang SW, Viswanath V, Eid SR, Petrus MJ, Earley TJ, Patapoutian A (2004) Noxious cold ion channel TRPA1 is activated by pungent compounds and bradykinin. Neuron 41:849-857.

Bautista DM, Jordt S-E, Nikai T, Tsuruda PR, Read AJ, Poblete J, Yamoah EN, Basbaum AI, Julius D (2006) TRPA1 mediates the inflammatory actions of environmental irritants and proalgesic agents. Cell 124:1269-1282.

Clapham DE (2003) TRP channels as cellular sensors. Nature 426:517-524.

Corey DP, García-Añoveros J, Holt JR, Kwan KY, Lin S-Y, Vollrath MA, Amalfitano A, Cheung EL-M, Derfler BH, Duggan A, Géléoc GSG, Gray PA, Hoffman MP, Rehm HL, Tamasauskas D, Zhang D-S (2004) TRPA1 is a candidate for the mechanosensitive transduction channel of vertebrate hair cells. Nature 432:723-730.

Gu JG, MacDermott AB (1997) Activation of ATP P2X receptors elicits glutamate release from sensory neuron synapses. Nature 389:749-753.

Inoue R, Okada T, Onoue H, Hara Y, Shimizu S, Naitoh S, Ito Y, Mori Y (2001) The transient receptor potential protein homologue TRP6 is the essential component of vascular $\alpha_{1}$-adrenoceptor-activated $\mathrm{Ca}^{2}$ permeable cation channel. Circ Res 88:325-332.

Jordt SE, Bautista DM, Chuang HH, McKemy DD, Zygmunt PM, Hogestatt ED, Meng ID, Julius D (2004) Mustard oils and cannabinoids excite sensory nerve fibres through the TRP channel ANKTM1. Nature 427:260-265.

Kamouchi M, Philipp S, Flockerzi V, Wissenbach U, Mamin A, Raeymaekers L, Eggermont J, Droogmans G, Nilius B (1999) Properties of heterologously expressed hTRP 3 channels in bovine pulmonary artery endothelial cells. J Physiol (Lond) 518:345-358.

Kelly S, Chapman V (2002) Spinal administration of capsazepine inhibits noxious evoked responses of dorsal horn neurons in non-inflamed and carrageenan inflamed rats. Brain Res 935:103-108.

Kobayashi K, Fukuoka T, Obata K, Yamanaka H, Dai Y, Tokunaga A, Noguchi K (2005) Distinct expression of TRPM8, TRPA1, and TRPV1 mRNAs in rat primary afferent neurons with $\mathrm{A} \delta / \mathrm{C}$-fibers and colocalization with Trk receptors. J Comp Neurol 493:596-606.

Kwan KY, Allchorne AJ, Vollrath MA, Christensen AP, Zhang DS, Woolf CJ, Corey DP (2006) TRPA1 contributes to cold, mechanical, and chemical nociception but is not essential for hair-cell transduction. Neuron 50:277-289.

Lin S-Y, Corey DP (2005) TRP channels in mechanosensation. Curr Opin Neurobiol 15:350-357.

Lu Y, Perl ER (2003) A specific inhibitory pathway between substantia gelatinosa neurons receiving direct C-fiber input. J Neurosci 23:8752-8758.

Minke B (2006) TRP channels and $\mathrm{Ca}^{2+}$ signaling. Cell Calcium 40:261-275.

Montell C, Birnbaumer L, Flockerzi V (2002) The TRP channels, a remarkably functional family. Cell 108:595-598.

Nagata K, Duggan A, Kumar G, García-Añoveros J (2005) Nociceptor and hair cell transducer properties of TRPA1, a channel for pain and hearing. J Neurosci 25:4052-4061.

Nakatsuka T, Gu JG (2001) ATP P2X receptor-mediated enhancement of glutamate release and evoked EPSCs in dorsal horn neurons of the rat spinal cord. J Neurosci 21:6522-6531. 
Nakatsuka T, Gu JG (2006) P2X purinoceptors and sensory transmission. Pflügers Arch 452:598-607.

Nakatsuka T, Ataka T, Kumamoto E, Tamaki T, Yoshimura M (2000) Alteration in synaptic inputs through C-afferent fibers to substantia gelatinosa neurons of the rat spinal dorsal horn during postnatal development. Neuroscience 99:549-556.

Nakatsuka T, Furue H, Yoshimura M, Gu JG (2002) Activation of central terminal vanilloid receptor- 1 receptors and $\alpha \beta$-methylene-ATP-sensitive $\mathrm{P} 2 \mathrm{X}$ receptors reveals a converged synaptic activity onto the deep dorsal horn neurons of the spinal cord. J Neurosci 22:1228-1237.

Namer B, Seifert F, Handwerker HO, Maihöfner C (2005) TRPA1 and TRPM8 activation in humans: effects of cinnamaldehyde and menthol. NeuroReport 16:955-959.

Nilius B, Voets T (2005) TRP channels: a TR(I)P through a world of multifunctional cation channels. Pflügers Arch 451:1-10.

Obata K, Katsura H, Mizushima T, Yamanaka H, Kobayashi K, Dai Y, Fukuoka T, Tokunaga A, Tominaga M, Noguchi K (2005) TRPA1 induced in sensory neurons contributes to cold hyperalgesia after inflammation and nerve injury. J Clin Invest 115:2393-2401.

Pedersen SF, Owsianik G, Nilius B (2005) TRP channels: an overview. Cell Calcium 38:233-252.

Shigetomi E, Kato F (2004) Action potential-independent release of glutamate by $\mathrm{Ca}^{2+}$ entry through presynaptic $\mathrm{P} 2 \mathrm{X}$ receptors elicits postsynaptic firing in the brainstem autonomic network. J Neurosci 24:3125-3135.

Story GM, Peier AM, Reeve AJ, Eid SR, Mosbacher J, Hricik TR, Earley TJ, Hergarden AC, Andersson DA, Hwang SW, McIntyre P, Jegla T, Bevan S, Patapoutian A (2003) ANKTM1, a TRP-like channel expressed in nociceptive neurons, is activated by cold temperatures. Cell 112:819-829.

Tölle TR, Berthele A, Zieglgänsberger W, Seeburg PH, Wisden W (1993) The differential expression of 16 NMDA and non-NMDA receptor sub- units in the rat spinal cord and in periaqueductal gray. J Neurosci 13:5009-5028.

Tominaga M, Caterina MJ (2004) Thermosensation and pain. J Neurobiol 61:3-12.

Tsuda M, Ueno S, Inoue K (1999) In vivo pathway of thermal hyperalgesia by intrathecal administration of $\alpha, \beta$-methylene ATP in mouse spinal cord: involvement of the glutamate-NMDA receptor system. Br J Pharmacol 127:449-456.

Wang H, Woolf CJ (2005) Pain TRPs. Neuron 46:9-12.

Wang H, Kohno T, Amaya F, Brenner GJ, Ito N, Allchorne A, Ji RR, Woolf CJ (2005) Bradykinin produces pain hypersensitivity by potentiating spinal cord glutamatergic synaptic transmission. J Neurosci 25:7986-7992.

Willis WD, Coggeshall RE (2004) Sensory mechanisms of the spinal cord. Ed 3. New York: Plenum.

Yajiri Y, Yoshimura M, Okamoto M, Takahashi H, Higashi H (1997) A novel slow excitatory postsynaptic current in substantia gelatinosa neurons of the rat spinal cord in vitro. Neuroscience 76:673-688.

Yang K, Kumamoto E, Furue H, Yoshimura M (1998) Capsaicin facilitates excitatory but not inhibitory synaptic transmission in substantia gelatinosa of the rat spinal cord. Neurosci Lett 255:135-138.

Yang K, Kumamoto E, Furue H, Li YQ, Yoshimura M (2000) Capsaicin induces a slow inward current which is not mediated by substance $\mathrm{P}$ in substantia gelatinosa neurons of the rat spinal cord. Neuropharmacology 39:2185-2194.

Yoshimura M, Jessell T (1990) Amino acid-mediated EPSPs at primary afferent synapses with substantia gelatinosa neurones in the rat spinal cord. J Physiol (Lond) 430:315-335.

Yoshimura M, Nishi S (1995) Primary afferent-evoked glycine- and GABAmediated IPSPs in substantia gelatinosa neurones in the rat spinal cord in vitro. J Physiol (Lond) 482:29-38.

Zurborg S, Yurgionas B, Jira JA, Caspani O, Heppenstall PA (2007) Direct activation of the ion channel TRPA1 by $\mathrm{Ca}^{2+}$. Nat Neurosci 10:277-279. 